\title{
Teatro, liberdade e repressão nos Festivais de Inverno de Ouro Preto, 1967-1979
}

\section{Theatre, Freedom and Repression in Winter Festivals of Ouro Preto, 1967-1979}

\author{
LeON Frederico Kaminski \\ Doutorando em História \\ Universidade Federal Fluminense \\ Rua dos Inválidos, 185/602, Rio de Janeiro, RJ, 20.231-047, Brasil \\ kaminski.historia@gmail.com
}

Resumo O Festival de Inverno de Ouro Preto, criado em 1967, foi uma das maiores promoções culturais do país na década de 1970. O evento oferecia uma diversidade de atividades, como cursos, concertos, exposições de arte e espetáculos teatrais, atraindo milhares de pessoas à cidade histórica. Em plena ditadura militar, era visto como espaço de liberdade de criação e experimentação artística, mantendo diálogo intenso com as propostas estéticas de vanguarda. No campo das artes cênicas, grupos como Corpo, Giramundo e Oficcina Multimédia tiveram gênese ligada ao evento. Temos como objetivo analisar o Festival de Inverno, entre 1967 e 1979, enquanto espaço de trocas culturais e de experimentações estéticas que possibilitaram a criação cênica para além das fronteiras disciplinares. Discutiremos também as ambiguidades e contradições do evento em relação às diferentes políticas do governo ditatorial, que ao mesmo tempo fomentava e reprimia a cultura.

Palavras-Chave teatro, ditadura, Festival de Inverno

Recebido: 10 nov. 2015 | Revisto: 31 jan. 2016 | Aprovado: 04 de fev. 2016 http://dx.doi.org/10.1590/0104-87752016000200004

Varia Historia, Belo Horizonte, vol. 32, n. 59, p. 327-355, mai/ago 2016 
Abstract The Winter Festival of Ouro Preto, established in 1967, was one of the largest cultural vehicles in the country of Brazil in the seventies. The event offered a wide range of activities including courses, concerts, art exhibitions, and theatrical performances that attracted thousands of people to the historical city. In the middle of military dictatorship, the Festival was perceived as a space for freedom of creation and artistic experimentation that dialogued intensively with the aesthetic vanguard propositions. In the field of the performing arts, the genesis of some artistic groups, the Corpo, Giramundo and Oficcina Multimedia are bound up with the event. We examine the Winter Festival from 1967 to 1979, considering it a space of cultural and aesthetic experimentation exchanges that allowed the scenic creation to go beyond the disciplinary boundaries. Likewise, we discuss the ambiguities and contradictions of the event in regard to the political differences during the dictatorial government, which supported culture, while simultaneously suppressing it.

KEYWORDS theatre, dictatorship, Winter Festival

Em julho de 1971, os principais jornais e revistas do país e do exterior noticiavam a prisão, na cidade de Ouro Preto, dos integrantes do Living Theatre. Grupo de vanguarda nova-iorquino, referência em experimentação teatral na década de 1960 - seu espetáculo Paradise Now foi um dos marcos do agitado ano de 1968. O episódio gerou grande repercussão, com campanhas pela libertação dos atores, manifestações em frente a embaixadas e consulados brasileiros no exterior e abaixo-assinados contando com a participação de personagens de relevo no cenário cultural internacional. Por denegrir a imagem do Brasil no exterior, os artistas estrangeiros foram expulsos do país em setembro daquele ano.

Ao pensarmos esse episódio específico para além do ato repressivo em si e questionarmos o porquê da presença do conceituado grupo teatral no interior de Minas Gerais, surgem diversas outras questões pertinentes à arte teatral e às políticas culturais do regime ditatorial brasileiro. O Festival de Inverno de Ouro Preto, do qual pretendiam 
participar, era então uma das maiores promoções culturais do país. Para muitos, um espaço de liberdade em meio ao clima asfixiante existente no Brasil após a promulgação do AI-5. Atraía milhares de pessoas que enchiam as ladeiras da cidade colonial. Constituiu-se como um espaço de vanguarda e de experimentação artística. Era, contudo, um evento organizado por uma instituição federal e fomentado pelas políticas culturais de um regime ditatorial, que reprimia e censurava. $O$ festival dialogava com o projeto de modernização conservadora do país. Essa condição lhe impingiu contradições e ambiguidades, que abordaremos neste trabalho.

O Festival foi também lugar de teatro e outras artes da cena. Em um momento de "(re/in)definição do campo teatral" brasileiro, devido ao recrudescimento da censura e da repressão (Hermeto, 2014, p.212), o Festival de Inverno constituiu-se como espaço multidisciplinar de experimentação da linguagem cênica. Grupos como o Corpo, Giramundo e o Oficcina Multimédia tiveram suas origens ligadas ao evento ouro-pretano. Quando ocorreram mudanças nas políticas culturais do governo federal para o teatro, foi lugar de debate e articulação da classe teatral mineira. Mas manteve relações ambíguas com a censura.

Este artigo tem como objetivo analisar o Festival de Inverno de Ouro Preto, entre 1967 e 1979, enquanto espaço de trocas culturais e de experimentações estéticas que possibilitaram a criação cênica para além das fronteiras disciplinares. Discutiremos também as ambiguidades e contradições do evento em relação às diferentes políticas do governo ditatorial, que ao mesmo tempo fomentava e reprimia a cultura. ${ }^{1}$

Os arquivos do Festival de Inverno compõem nosso principal material de pesquisa. São constituídos de documentação diversa, como correspondências, catálogos, relatórios, notas para a imprensa, recortes de jornais, etc. Temos claros seus limites e incompletudes, seus silêncios. Materiais produzidos em tempos de repressão, outros que se perderam

1 Utilizamos como base interpretativa uma série de estudos que buscam compreender as complexas relações entre sociedade civil e regimes autoritários. REIS, 2014; MOTTA, 2014; GARCIA, 2013; ROLLEMBERG; QUADRAT, 2011. 
em mãos diversas. Mas também documentação valiosa, que nos permite espreitar cenas experimentais no palco barroco, luzes e sombras do teatro brasileiro.

\section{OS FESTIVAIS DE INVERNO}

A primeira edição do Festival de Inverno, em 1967, foi fruto da convergência de interesses de diferentes grupos de artistas e instituições. $\mathrm{O}$ evento obteria, naquele ano, grande êxito e excelente repercussão nos meios jornalísticos, artísticos e políticos, garantindo financiamento e apoio para as edições seguintes. A ideia fundamental para o surgimento do Festival, e que seria sua base estrutural até 1979, era a organização de cursos intensivos de arte a serem realizados durante as férias escolares de julho. Seu formato fora baseado em modelo bastante difundido na Europa, principalmente entre os festivais de música erudita: cursos que duravam um mês, com apresentações dos alunos ao final e concertos e espetáculos ao longo do evento. Diferia de outros festivais por não se dedicar somente a uma forma de expressão artística. O Festival de Inverno congregava em um único evento diversas práticas culturais e artísticas, como a música erudita, as artes plásticas, a literatura, o cinema e o teatro.

Nos primeiros anos da ditadura, de 1964 a 1968, havia uma repressão relativamente moderada no âmbito cultural, se comparada à coerção infligida aos movimentos sociais e políticos. Derrotada politicamente, a esquerda parecia vitoriosa no campo cultural. Uma resistência cultural ao regime e aos valores por ele defendidos podia ser vista e ouvida através de manifestações artísticas, seja entre os defensores da estética nacional-popular ou da arte de vanguarda. A cultura de esquerda e o pensamento crítico eram tolerados por setores militares que estavam no governo, desde que "o artista engajado ficasse dentro do círculo de giz do mercado e dos circuitos culturais de classe média” (Napolitano, 2014, p.101). Tal situação seria modificada em 1968, com a implementação do AI-5 e o recrudescimento da censura e da repressão. Não que não houvesse censura e repressão antes dessa data. Havia, mas as consequências 
provocadas pelo Ato desarticulou boa parte das ações da esquerda no campo cultural. Muitos artistas foram presos ou partiram para o exílio, vozes foram caladas.

Algumas memórias relacionadas à criação do Festival de Inverno fazem referência a esse período de agitação cultural anterior ao AI-5. Segundo o artista plástico Álvaro Apocalypse, o ideal dos fundadores do Festival era o "sonho de reunir a juventude em torno do ideal de liberdade, confraternização, camaradagem, criatividade e Arte que caracterizou aquelas férias em Ouro Preto em 1967". ${ }^{2}$ Haroldo Mattos seria mais incisivo: "O Festival de Inverno foi iniciado na época do governo militar (...). A primeira ideia foi a criação de um curso de férias em Ouro Preto, enquanto canal de afirmação para os artistas e intelectuais perseguidos" (apud Ribeiro, 1997, p.139).

Apesar de certa idealização nos relatos acima, em relação a um caráter de resistência na gênese do evento, este foi um dos fatores presentes em seu surgimento. Em 1967, no âmbito da Escola de Belas Artes (EBA) da UFMG, da qual Mattos era diretor, militares locais solicitavam que a universidade tomasse providências em relação a professores indiciados em inquérito policial militar. Denúncia realizada por ex-alunos da instituição que haviam sido preteridos na contratação para docentes. Acusavam o diretor de dar preferência a elementos esquerdistas. ${ }^{3} \mathrm{~A}$ ideia principal para a criação do Festival pode não ter sido a de abrir um canal para os artistas perseguidos, mas este foi um dos ingredientes presentes no evento.

A proposta de realizar um festival em Ouro Preto surgiu a partir da movimentação de dois grupos diferentes de Belo Horizonte: o dos artistas plásticos ligados à UFMG e o dos músicos vinculados à Fundação de Educação Artística (FEA). A circulação de informações pelo meio cultural mineiro propiciou a aproximação entre os grupos e o

2 APOCALYPSE, Álvaro. Questionário, fev./1993, Biblioteca Universitária (BU) - UFMG, Belo Horizonte, Col. Esp., FI, cx. 1967, pasta "Levantamento de Informações sobre o $1^{\circ}$ Festival de Inverno da UFMG".

3 BU - UFMG, Belo Horizonte, Col. Esp., AESI, cx. 1967/5, maço 08, folhas 61-71. 
delineamento do projeto do festival, que contou com o apoio da prefeitura de Ouro Preto e do Conselho de Extensão da universidade. O financiamento ficou por conta do governo estadual. Além do interesse cultural, o estado e o município visavam fomentar o turismo na cidade. ${ }^{4}$ Já a UFMG, buscava promover o extensionismo como uma das partes constituintes da reforma universitária, que já vinha sendo realizada dentro da instituição (Pimenta, 1984).

Os dois campos artísticos proponentes do Festival foram os que tiveram maior protagonismo ao longo do período pesquisado. O teatro e outras artes eram incorporados conforme o evento crescia de tamanho e ampliava a demanda. O Festival, que começou com 252 cursistas, chegou a contar com 739 alunos inscritos em 1972. A Escola de Belas Artes reunia professores que faziam parte da movimentada cena da vanguarda das artes plásticas belo-horizontina (Ribeiro, 1997) e incorporava tais tendências em seus projetos em relação ao Festival. O mesmo ocorria com os professores da Fundação de Educação Artística, que havia surgido, em 1963, como uma alternativa ao ensino fortemente conservador existente no meio musical mineiro. A partir de 1970, a Fundação e o Festival de Inverno deram uma guinada em direção à vanguarda, integrando um importante movimento de renovação e circulação da música erudita de vanguarda na América Latina (Paoliello, 2007; Lovaglio, 2010). Além do experimentalismo artístico, buscava-se também um experimentalismo didático, com formas mais livres de ensino. As duas instituições conseguiram direcionar seus interesses em projetos de médio prazo que permitiram uma estabilidade nos setores de artes plásticas e música, em contraste com a presença das artes cênicas no evento.

A forma como era organizado o Festival proporcionava um contato intenso, constante e informal entre professores, artistas e estudantes. Era um convívio de muitas horas diárias e que durava um mês inteiro. A respeito dessa convivência, o crítico teatral Yan Michalski comentava:

4 Carta do Prefeito de Ouro Preto ao Reitor da UFMG, 20 mar. 1967, BU - UFMG, Col. Esp., FI, cx. 1967, pasta 1.5. Turismo é a indústria que a Hidrominas sabe aproveitar. Diário de Minas (Belo Horizonte), 24 jul. 1969, BU - UFMG, Belo Horizonte, Col. Esp., FI, cx. 1969/ Recortes. 
Vive-se intensamente em Ouro Preto. Como nos festivais da Grécia antiga, como nos atuais festivais de Avignon, instala-se ali um clima de festa - festa que não tem no caso o sentido de lazer, mas sentido de um tempo diferente, mais pleno e livre do que o tempo da rotina diária de cada um dos participantes nas suas respectivas cidades de origem. $\mathrm{O}$ fato de cada um estar longe de seus compromissos e hábitos normais favorece a espontaneidade de comportamento e transforma os estudantes e professores numa provisória coletividade democrática e fraterna. Nesse clima de festa, cada minuto tem peso de ouro e precisa ser aproveitada até a última gota. ${ }^{5}$

Michalski, em seu texto, ressalta não somente o convívio, mas o relativo clima de liberdade e de democracia existente no Festival durante aqueles anos de repressão: o cotidiano flui "numa intensidade diferente, que favorece o encontro com o próximo e dá a cada minuto um sentido quase impossível de alcançar nas condições em que se vive no resto do país". Compunham também essa atmosfera as milhares de pessoas que iam à cidade dos inconfidentes atraídas pelo Festival, mas que não participavam dele oficialmente, como cursistas, professores ou artistas convidados. Elas enchiam as ruas e praças com um colorido e animação especiais, transformando a antiga vila colonial em ponto de encontro de jovens de todo o país e que lá encontravam um pouco de ar, diante do sentimento de asfixia que se vivia durante a ditadura.

Segundo Beatriz Vieira (2007, p.332), a experiência histórica dos anos setenta está marcada pela metáfora do "sufoco", devido à "opressão asfixiante da vida cotidiana sob a ditadura militar". O crítico teatral descreve uma paisagem que antagonizava com o clima opressivo existente no contexto nacional, mostrando Ouro Preto como um espaço diverso, mais livre. O Festival de Inverno construía-se como um espaço de liberdade, de experimentalismo estético e didático, embora houvesse suas contradições, como veremos adiante. Num período em que a experiência

5 MICHALSKI, Yan. Ouro Preto: ritual da integração. Jornal do Brasil (Rio de Janeiro), caderno b, p.04, 28 jul. 1972. 
histórica é marcada pela metáfora do sufoco, o Festival de Inverno seria, para alguns, um local no qual se podia respirar, ao menos por um mês.

\section{AS ARTES CÊNICAS NOS FESTIVAIS DE INVERNO ${ }^{6}$}

Embora as áreas de artes plásticas e música tivessem proeminência maior na organização do evento, as artes cênicas estiveram presentes desde o primeiro Festival. Mesmo com altos e baixos, foi parte integrante do evento. Em 13 anos foram apresentados mais de 120 espetáculos cênicos. ${ }^{7}$ Ao passearmos pela programação das diferentes edições, cruzamos com artistas de prestígio no cenário nacional. Passaram pelos palcos do evento figuras como Paulo Autran, Maria Della Costa, Eva Wilma, Lilian Lemmertz, Othon Bastos, Glauce Rocha, Rubens de Falco, Emilio di Biasi, Tônia Carrero, Cécil Thiré, Pedro Paulo Cava, José Celso Martinez, Décio Otero e Ruth Rachou, entre outros.

Se por um lado os invernos ouro-pretanos contaram com a presença de atores e diretores importantes do cenário nacional, por outro houve grande participação de grupos teatrais não profissionais (estudantis, universitários, amadores, independentes...) nos Festivais de Inverno. Mais de dois terços dos espetáculos cênicos apresentados poderiam ser enquadrados neste perfil. Esse quadro refletia a própria configuração do teatro nacional, tendo em vista as dificuldades de profissionalização fora do eixo Rio-São Paulo. Contudo, demonstra também o direcionamento e o diálogo com um dos principais públicos do Festival, os jovens, ao promover os grupos estudantis e a extensão universitária. Visto que

6 Utilizamos a noção de "artes cênicas" (ou artes da cena, performing arts), que consiste na apresentação direta do produto artístico, sem intermédio de um meio de comunicação, "onde o que conta é a imediatidade da comunicação com o público por meio dos performers (atores, dançarinos, cantores, mímicos etc.)", não se restringindo ao teatro falado (PAVIS, 2008, p.27, p.284).

7 Os catálogos e as demais fontes presentes nos arquivos do Festival não permitem, com poucas exceções, uma análise aprofundada dos espetáculos. Da maioria das apresentações temos somente o nome da peça, do autor e do grupo. Contudo, a partir desse material, podemos traçar algumas análises sobre a presença das artes cênicas nos Festivais de Inverno. 
os cursos eram o cerne do Festival, os espetáculos possuíam um papel complementar, mas importante. Eles eram voltados não somente para os participantes do evento, mas também para as pessoas da cidade, turistas e outros visitantes. A frequência dos moradores nas atividades era entendida como fator de aproximação com a comunidade, uma ação extensionista da universidade através da difusão cultural. ${ }^{8}$

A partir de uma observação da programação do evento, podemos perceber presença maior de espetáculos ou atividades ligadas ao experimentalismo da linguagem cênica, embora também estivessem presentes outras propostas estéticas. Porém, não havia, como nos dois setores pioneiros (música e artes plásticas), um projeto em médio prazo ou uma instituição que projetasse no Festival um espaço de formação contínua. O setor, que iniciou em 1970, teve coordenadores de diferentes perfis a sua frente. Nenhum possuindo o experimentalismo como marca principal da carreira. ${ }^{9} \mathrm{O}$ Festival de Inverno, contudo, configurava-se como um espaço artístico de vanguarda. Enquanto a produção teatral vinculada à estética nacional-popular sofria refluxos em função da repressão e da censura mais rígidas entre 1968 e o início do processo de abertura política (Hermeto, 2014), o teatro de vanguarda demonstrava proeminência no mesmo período (Leão, 2009; Cavalcanti, 2012).

Maria Fernanda Pinta (2013, p.28), ao estudar a cena experimental argentina, propõe a noção de teatro expandido. Para a autora, o teatro experimental, ao questionar o cânone teatral caracterizado pelo realismo/naturalismo e pelo "textocêntrismo", expandia-se para além das fronteiras disciplinares, uma "expansão do teatro a outras práticas artísticas e estéticas”. No caso portenho, o Instituto Di Tella, que abrigava e fomentava propostas artísticas de vanguarda provenientes de diferentes campos, das artes plásticas e da música eletrônica às artes visuais e

8 LACERDA, Roberto. Extensão universitária como difusão cultural, BU - UFMG, Belo Horizonte, Col. Esp., FI, cx. 1972/2, pasta 2.4.

9 Júlio Varella (1970), Sylvia Orthof (1971), diretora do Teatro do SESI-DF; Ítalo Mudado (1972-1974), diretor do Teatro Clássico; e Haydée Bitencourt (1975), diretora do Teatro Universitário (UFMG). Dulce Viegas coordenou o curso de dança em 1975 e 1976. 
cênicas, foi um espaço privilegiado para a experimentação da linguagem teatral numa perspectiva expandida e interdisciplinar. Os Festivais de Inverno, à semelhança da instituição argentina, proporcionava contatos e trocas frequentes entre as diferentes disciplinas artísticas. Um espaço de circulação cultural que permitia tanto que o teatro se expandisse a outras expressões artísticas quanto um movimento inverso, das artes plásticas e da música em direção à teatralidade.

Os cursos da área cênica, assim como vários outros, eram criados em razão da demanda e do crescimento do Festival, abertos conforme surgiam as necessidades de diversificação e ampliação no número de vagas. Apesar da ausência de um projeto delineado para este campo artístico, houve o empenho em oferecer cursos de alto nível, como nas demais áreas, contratando figuras de relevo, como Klauss Viana, Sylvia Orthof, Amir Haddad, Baldur Liesemberg, Flavio Império, Jura Othero, Yan Michalski, Raul Belém, Celso Nunes, Jonas Bloch e Oscar Araiz, entre outros.

O primeiro curso de teatro, inicialmente não programado, surgiu a partir de uma demanda específica. Em 1969, com o intuito de promover uma maior integração do evento com os moradores de Ouro Preto, a organização do Festival decidiu realizar um espetáculo encenado por atores locais. Com mais de cem candidatos, a direção do Festival decidiu criar o Curso Experimental de Teatro. ${ }^{10}$ Desse primeiro curso surgiu o Grupo Experimental de Teatro de Ouro Preto (GETOP). Vários dos integrantes já possuíam alguma experiência, mas a partir do novo grupo vislumbravam novas possibilidades, de realizar um teatro menos tradicional e movimentar a cena local. Os membros do grupo continuaram fazendo os cursos e apresentaram a criação coletiva Ômega, na abertura do Festival de 1971. Os cursos de teatro foram ministrados somente entre 1969 e 1976, pois perderam espaço com o processo de diminuição da estrutura do evento.

10 Separata da Revista da UFMG, n. 18, p.18, 1968/1969, BU - UFMG, Belo Horizonte, Col. Esp., FI, cx. 1969/1, pasta 1.3 . 
O Festival também abriu espaço para o campo da dança, alcançando destaque no cenário nacional (Aquino, 2005). Rolf Gelewski, Clyde Morgan, Klaus Vianna, Beverly Crook e Marilene Martins foram alguns personagens que lecionaram no evento. $\mathrm{O}$ maior destaque nessa área foram os cursos ministrados pelos bailarinos do Ballet Contemporâneo da Cidade de Buenos Aires, em 1973 e 1974. Segundo Inês Bogéa (2007, p.22), o argentino Oscar Araiz, mesmo em tempo de ditaduras, "voltava-se sem medo para as questões sociais, transfiguradas numa linguagem relativamente livre de panfletarismo". Dos cursos participariam os irmãos Pederneiras. Rodrigo foi, em 1973, estudar com Araiz na cidade portenha (Reis, 2008). Em 1975, os irmãos fundaram o Grupo Corpo, um dos principais grupos de dança do país.

Para além da dança em si, é importante pensarmos sua aproximação com o teatro. Vários professores da área integraram o corpo docente dos cursos de teatro, como Klauss Viana, Rolf Gelewski, Beverly Crook e Oscar Araiz. Eles contribuíram com aulas de dança, reeducação muscular, movimento para atores e expressão corporal. Esta aproximação fazia parte das transformações que aconteciam nas artes cênicas. No campo teatral, o experimentalismo buscava alternativas ao cânone dramático ocidental, caracterizado pelo realismo/naturalismo e no predomínio do texto dramático sobre a cena. Como contraponto, propunha-se a teatralidade, o predomínio dos aspectos cênicos e da performance dos atores sobre o texto (Pinta, 2013). Segundo Luiz Carlos Maciel (2005, p.108), abandonava-se a defesa do texto prévio em favor da valorização do espetáculo puro, da teatralidade. Para o autor, os atores passavam a ser "valorizados pelo trabalho corporal, pouco importando a deficiência das inflexões" da fala. Em consequência, as aulas de expressão corporal passariam a ser mais procuradas que as de técnica vocal.

Klauss Viana estava em sintonia com essa tendência. Ele havia sido responsável pela coreografia de Roda Viva, dirigido por José Celso Martinez, e pela preparação corporal do elenco de Hoje é dia de Rock, de José Vicente, montado pelo Teatro Ipanema, dois marcos do teatro experimental no país. Em 1972, ano em que foi professor do evento, o bailarino criticava a prática dos atores serem simples "marionetes nas 
mãos dos diretores" e defendia que o trabalho de expressão corporal fosse usado para quebrar as barreiras, "cada um criando livre de formas estabelecidas, à sua própria maneira" (apud Leão, 2009, p.53-54). Oscar Araiz acreditava ser impossível encarar a dança como algo distinto do teatro, ambas se interpenetravam, visto que o próprio teatro, considerado como "arte total, reúne em si a voz, a dança, a música e o canto". ${ }^{11}$ A relação entre teatro e dança, nos Festivais de Inverno, transpassava as barreiras disciplinares em direção à teatralidade e à performance cênica.

Dois outros grupos cênicos surgidos em torno do Festival de Inverno não estavam ligados ao setor de teatro e dança, possuíram gênese multidisciplinar: o Giramundo e o Oficcina Multimédia. O artista plástico Álvaro Apocalypse, após contato com o teatro de bonecos na França em 1969, produzira alguns títeres para encenações caseiras. Pouco tempo depois, foi convidado pelo produtor Júlio Varella para se apresentar no Festival de Inverno. Surgia, em 1971, o Giramundo - Teatro de Bonecos, formado inicialmente por Álvaro Apocalypse, Terezinha Veloso e Maria do Carmo Vivacqua Martins, artistas plásticos e professores da UFMG. O Giramundo concebia os bonecos como "esculturas em movimentos" e entendia as cenas como quadros, em sua composição. Para Apocalypse (2001, p.40), o teatro de bonecos era "uma região fronteiriça, um entre -lugar no qual confundem-se e misturam-se todas as artes". Trata-se, por um lado, da aplicação das concepções estéticas e metodológicas das artes plásticas e, por outro, a diluição das fronteiras disciplinares em prol da obra artística e da performance cênica, integrando teatro, música e artes plásticas.

Ao longo da década, o grupo foi presença constante nos Festivais de Inverno. Em 1976, ministrou um curso de teatro de bonecos, do qual resultou na encenação de Retablo de Maese Pedro, ópera de Manuel de Falla, a pedido do setor de música em homenagem ao centenário do autor. O espetáculo, inovador para os parâmetros nacionais do teatro de bonecos da época, alcançou repercussão nacional. Em 1976, a UFMG disponibilizaria espaço para a oficina do grupo e passou a fornecer

$117^{\circ}$ Festival de Inverno: relatório, p.21, BU - UFMG, Belo Horizonte, Col. Esp., FI, cx.1973/1. 
recursos para a montagem de seus espetáculos (Malafaia, 2006). Em 1979, junto com o músico Lindemberg Cardoso, os integrantes do Giramundo promoveram a oficina interdisciplinar Som/Forma/Movimento, que visava integrar esses elementos por meio do "potencial técnico e expressivo do teatro de bonecos".12 Oficina repetida, posteriormente, no Teatro Aurimar Rocha, espaço voltado para o teatro de bonecos e mantido pelo Serviço Nacional de Teatro - SNT (Braga, 2007). ${ }^{13}$

O outro grupo que surgiu em torno do Festival foi o Oficcina Multimédia, fruto dos cursos ministrados pelo músico argentino Rufo Herrera entre 1976 e 1979. As oficinas propunham a "integração de diferentes níveis e tipos de experiência no fazer artístico, para busca coletiva de outras possibilidades de expressão do pensamento contemporâneo através da arte". ${ }^{14}$ Vários alunos vieram a integrar o grupo, que fez sua primeira apresentação em 1978, Sinfonia de Ré-Fazer, resultado final da oficina realizada no Festival de Inverno. O grupo acabaria acolhido pela Fundação de Educação Artística, da qual Rufo Herrera e outros integrantes eram professores ou alunos (Medeiros, 2007).

A proposta de Rufo Herrera (2007, p.10) era "abordar a criação com uma visão integral, tomando como princípio o fato de que todas as formas de expressão artística possuem elementos análogos de estruturação, tendo como ponto de unidade o conteúdo estético inerente à obra de arte". Para o músico, haveria uma contradição entre os avanços sonoros da música contemporânea e a postura dos intérpretes no palco, ou seja, a forma da performance dos concertos estaria ultrapassada. Desta forma, o argentino buscava reformular as relações entre música

$1210^{\circ}$ Festival encerra suas atividades com ópera para bonecos, BU - UFMG, Belo Horizonte, Col. Esp., FI, cx. 1976/1, pasta 1.5b. 13 Festival de Inverno [material de divulgação], BU - UFMG, Belo Horizonte, Col. Esp., FI, cx. 1979/1.

13 Este campo artístico passou por transformações acentuadas nos anos 1970, tanto em relação a inovações em termos de linguagem quanto a sua organização e profissionalização. Em 1973, foi criada a Associação Brasileira de Teatro de Bonecos e, três anos depois, há a criação de um setor específico para o gênero no SNT. BRAGA, 2007.

$1413^{\circ}$ Festival de Inverno [material de divulgação], BU - UFMG, Belo Horizonte, Col. Esp., FI, cx.1979/1. 
e cena. A concepção era a de reunir artistas de diferentes disciplinas e que fossem produzidos, em processo de criação coletiva de forma experimental, os espetáculos que integrassem as artes da cena, a música de vanguarda e outras artes (Herrera, 2007; Paoliello, 2007). Ione de Medeiros (2007, p.15), aluna do Festival e posteriormente diretora do Multimédia, aponta que, especificamente ao que se refere à linguagem cênica, a peculiaridade do grupo se dá em função de terem entrado no teatro através da música, transpondo para a "encenação teatral o caráter de abstração próprio da linguagem musical”.

O Festival de Inverno, como espaço de trocas e de circulação cultural, possibilitou uma diversidade de contatos entre pessoas e formas artísticas. Foi também um lugar que permitiu o experimento e o diálogo entre diferentes linguagens. Não só ao teatro foi possível expandir-se para além das fronteiras disciplinares, mas também a outras artes, que se expandiram e adentraram o campo cênico. Experiências que extrapolaram os limites do próprio Festival e contribuíram para um repertório das artes cênicas nacional.

\section{O FESTIVAL COMO FÓRUM TEATRAL}

Para além das experiências estéticas, o Festival de Inverno funcionou também como espaço de articulação e realização de eventos paralelos, mas integrados à sua programação. Foram produzidos, por exemplo, festivais internacionais de dança e de teatro de bonecos. Em 1973, foi promovido o Seminário sobre Teatro. Mediado por Décio de Almeida Prado, contou com a participação de Yan Michalski, Sábato Magaldi, Celso Nunes, Joel Pontes e Oscar Araiz, entre outros. A partir de um resumo dos debates que consta no relatório do Festival, podemos perceber alguns dos temas abordados no seminário.

Entre as questões levantadas estava a do público teatral. Joel Pontes atribuía a diminuição do público "aos diretores incapazes e ignorantes, que manipulam”, sem escrúpulos, os textos dramáticos em nome de um experimentalismo duvidoso. Por sua vez, Michalski entendia que havia uma forte divisão no teatro brasileiro, estética e de público, cada um a 
seu gosto, entre o teatro "digestivo", comercial, e o teatro de vanguarda, radical. Para o crítico, entre esses dois extremos, não havia um "teatro do meio-termo", sem demasiada ênfase na linguagem experimental, mas que fosse inteligente e "preocupado com temas importantes". Celso Nunes, por sua vez, acreditava não haver uma crise de público, mas sim uma crise em função da atuação da censura no teatro, que tolhia as possibilidades de fala. Magaldi também abordou o problema da censura. Apontava-a como responsável pelo "gradativo empobrecimento da criação de peças genuinamente nacionais", referindo-se à diminuição da produção nacional-popular. ${ }^{15}$

Apesar de termos somente alguns fragmentos do debate, é possível percebermos algumas questões centrais referentes ao teatro brasileiro naquele momento, como a questão do público, da censura, das críticas ao teatro experimental e do esvaziamento da produção "genuinamente nacional". Quadro que sofreria algumas modificações a partir de 1974, com o início do processo de abertura, quando houve a troca da direção do Serviço Nacional de Teatro (Garcia, 2013), e a emergência de um teatro "meio-termo", híbrido, entre os interesses comerciais e o engajamento (Hermeto, 2014).

Nesse sentido, foi sintomática a "ausência inesperada e inexplicável" de Felinto Rodrigues Neto, diretor do SNT, que participaria do seminário, com o tema "o teatro e o governo". Sua presença na programação causou descontentamento. A coordenação do seminário recebeu carta dizendo ser lamentável o nome do diretor do SNT estar entre os participantes. $\mathrm{O}$ autor da missiva discorria sobre a incompetência do gestor e dos casos de corrupção no órgão, que estagnavam a capacidade de fomento à produção teatral. ${ }^{16}$ As críticas tinham seus fundamentos. Sem experiência na área teatral e "praticamente um interventor", o SNT sofreu longo declínio sob sua gestão (Michalski, 1985, p.33). Sem diálogo com

$157^{\circ}$ Festival de Inverno: relatório, p.17-23, BU - UFMG, Belo Horizonte, Col. Esp., FI, cx.1973/1. $167^{\circ}$ Festival de Inverno: relatório, p.18, BU - UFMG, Belo Horizonte, Col. Esp., FI, cx. 1973/1. Carta de Luis Carlos Heydmann a Ítalo Mudado, BU - UFMG, Belo Horizonte, Col. Esp., FI, cx. 1973/3, pasta 3.3 . 
a classe teatral, Rodrigues Neto estava alinhado com o projeto repressivo da ditadura. Foi substituído, em 1974, por Orlando Miranda, representante dos empresários teatrais do Rio, que reabriu o diálogo com a classe teatral e implantou medidas de fomento ao teatro. Algumas das políticas visavam descentralizar os incentivos para além do eixo Rio-São Paulo (Garcia, 2013), que incluíam a aproximação com o teatro amador.

O Festival de Inverno organizou dois outros momentos de debate acerca do teatro. Em 1974, foi organizado o II Seminário Nacional de Teatro, realizado em São João del Rei, ${ }^{17}$ com o tema "O ensino de teatro no Brasil”. Foi promovido, em conjunto, o Festival Brasileiro de Teatro Amador, com a participação de 14 grupos. É importante percebermos que esse evento aconteceu no mesmo ano da fundação da Federação Nacional de Teatro Amador (FENATA), resultado da articulação de núcleos teatrais de diferentes estados. Naquele contexto, respaldavam, não sem atritos, a gestão de Orlando Miranda frente ao SNT, tendo em vista as possibilidades de financiamento ao teatro amador. Outro ponto importante eram políticas de descentralização dos incentivos, pois, fora do eixo Rio-São Paulo, praticamente todo o teatro seria amador (Dangelo, 2010).

Nesse momento de articulação e mobilização da classe teatral, foi proposto ao Festival que suas atividades, em 1976, estivessem direcionadas às lideranças teatrais, os diretores, e não aos atores. Desta forma, o curso de teatro seria substituído por um seminário sobre Stanislawski, financiado pelo SNT. Ao mesmo tempo, seria realizado um encontro de diretores de grupos teatrais mineiros. A razão do pedido era a de promover uma "mobilização geral para facilitar o cadastramento" dos grupos à Federação de Teatro do Estado de Minas Gerais, recém-criada. Argumentava-se que, fora do eixo Rio-São Paulo, “o único teatro que se

17 De 1970 a 1977, o Festival agregou outras cidades à programação. A sede mantinha-se em Ouro Preto, com as principais atividades. O propósito era vincular o turismo cultural à atividade extensionista. A ideia de Extensão era alargada, em diálogo com o ideário modernizante do governo. Passava a ser vista como ferramenta de inserção da universidade no processo de desenvolvimento regional e nacional. Catálogo, BU - UFMG, Belo Horizonte, Col. Esp., FI, cx. 1973/1. 5 Festival de Inverno: catálogo, BU - UFMG, Belo Horizonte, Col. Esp., FI, cx. $1971 / 1$. 
faz é realmente amador" e, nesse sentido, o fortalecimento da federação local, em articulação com a nacional, visava criar uma infraestrutura no estado. ${ }^{18}$

A programação proposta foi realizada em Belo Horizonte, dentro das atividades do Festival de Inverno, que contou também com um encontro de diretores de escolas dramáticas do país. ${ }^{19}$ No documento final do encontro de diretores, veiculado na imprensa, foi incorporado e atualizado o relatório do seminário promovido em 1974. Constavam diversas propostas sobre o ensino de teatro, que seriam encaminhadas ao ministro da Educação. Faziam considerações também em relação aos cursos livres de teatro, apontando que "os cursos livres atendem à situação do Teatro, de caráter amador, na maioria dos Estados brasileiros, e por isso devem ser auxiliados pelo governo". 20

Em entrevista de Pedro Paulo Cava a Jota Dangelo (2010, p.465-509), no final dos anos oitenta, a relação entre a organização do teatro amador e o SNT foi motivo de discordância entre os interlocutores. Ambos estiveram envolvidos na criação das federações nacional e mineira de teatro amador. Cava, olhando criticamente para o passado, via que a criação das entidades interessava ao governo, como forma de atrelar os grupos teatrais amadores à estrutura do Estado, além de respaldar Orlando Miranda frente ao SNT. Um dos resultados teria sido a não profissionalização dos grupos teatrais, muitos em condição semiprofissional, que ficaram presos aos incentivos estatais. Dangelo, por sua vez, discordava, alegando que a criação da FENATA e das federações estaduais permitiu a organização dos grupos teatrais, o que lhes facilitava fazer reivindicações na esfera nacional. Algo que não seria possível se os grupos continuassem isolados.

18 Teatro, BU - UFMG, Belo Horizonte, Col. Esp., FI, cx. 1976/1, pasta 1.7. Festival de Inverno faz em BH $1^{\circ}$ Encontro Nacional de Artes para comemorar $10^{\circ}$ ano, BU - UFMG, Belo Horizonte, Col. Esp., FI, cx. 1976/1, pasta 1.5b.

19 Festival de Inverno faz em BH $1^{\circ}$ Encontro Nacional de Artes para comemorar $10^{\circ}$ ano, BU UFMG, Belo Horizonte, Col. Esp., FI, cx. 1976/1, pasta 1.5b.

20 Propostas para mudar a realidade de nossa arte. Estado de Minas (Belo Horizonte), 09 jul. 1976; BU - UFMG, Belo Horizonte, Col. Esp., FI, cx. 1976/Recortes. 
Como nesse caso específico, as relações entre a classe teatral e o SNT na gestão Orlando Miranda, como aponta Miliandre Garcia (2013), suscitam opiniões controversas e revelam questões paradoxais. Resultado das próprias ambiguidades e contradições das políticas culturais do regime ditatorial.

\section{O TEATRO VIVO DA DITADURA}

Em tempos de contracultura, Ouro Preto, durante o Festival de Inverno, tornou-se ponto de convergência de jovens, artistas, intelectuais, artesãos, viajantes e hippies. Segundo o Diário da Tarde, o Festival era um gigantesco imã que atraia toda a "hipolândia nacional". Além desses personagens, havia grande contingente de turistas, em seu perfil mais tradicional. As estatísticas publicadas pela imprensa mostravam números não abaixo de 100 mil visitantes na cidade durante o evento. Em 1971, teria chegado a $350 \mathrm{mil}^{21}$

Em 1972, a revista Veja publicou matéria intitulada "A cidade dos Jovens". A reportagem abordava o evento e dividia os participantes em dois grupos: os obedientes e os rebeldes, ou os do "festival de arte" e os do "festival paralelo". Os primeiros - que não eram, necessariamente, tão obedientes assim - era composto pelos cursistas regularmente matriculados no evento. O segundo grupo, o dos "rebeldes", agregava as pessoas que iam para Ouro Preto "curtir" a cidade. A "cidade dos jovens" descrita era uma cidade tanto da cultura quanto da "perdição".22 O caráter festivo, porém, também possuía uma perspectiva contestadora da sociedade. Por ser contraproducente, a boemia é uma afronta contra a sociedade disciplinar, uma atitude transgressora apropriada pela juventude (Pedroso, 2009). A congregação humana "amistosa e festiva era percebida

21 Onda de hippies em Ouro Preto. Diário da Tarde (Belo Horizonte), 04 jul. 1974, BU - UFMG, Belo Horizonte, Col. Esp., FI, cx. 1974/Recortes. PM, Dops e mais quatro delegacias vão vigiar Inverno em Ouro Preto. Estado de Minas (Belo Horizonte), 01 jul. 1972, BU - UFMG, Belo Horizonte, Col. Esp., FI, cx. 1972/Recortes.

22 Cidade dos Jovens. Veja (São Paulo), n. 203, p.60, 26 jul. 1972. 
como um evento de força política e reativa naquele contexto fechado e desagregador" (Vieira, 2007, p.221).

O comportamento de parte dos jovens que participavam do Festival de Inverno chocava as autoridades e os setores mais conservadores de Ouro Preto. Não demorou, o desbunde, a boemia e o consumo de drogas começaram a ser reprimidos na cidade. Atentos ao caráter subversivo das propostas de mudanças comportamentais, os órgãos de repressão passaram a coibir certas manifestações, ação normalmente justificada pelo combate às drogas. A partir de 1970, começou-se a realizar uma grande quantidade de prisões, chegando a centenas, durante o Festival. ${ }^{23}$

Contudo, mesmo com o avanço do aparelho repressivo em Ouro Preto, o Festival teve continuidade sem maiores percalços. Partindo desse detalhe, podemos observar um pouco das ambiguidades existentes na relação entre o Festival e o governo ditatorial. Com o sucesso das primeiras edições, o evento tornou-se o principal projeto de extensão da UFMG e um dos maiores do país, contando com enorme prestígio nos círculos culturais, políticos e econômicos do estado. Com grande repercussão na imprensa, também era prestigiado nos setores governamentais ligados à cultura. Sua realização contava com apoio e verbas do Ministério da Educação e Cultura, do Conselho Nacional de Cultura e da Funarte. Tratava-se, assim, de um evento de vanguarda, que propiciava uma sensação de liberdade, tido como de resistência, e que era financiado por um regime ditatorial.

Esse caráter ambíguo e contraditório pode ser compreendido pela própria estrutura política do regime, que acomodou grupos com perspectivas ideológicas distintas, mas que se reuniam em torno de algumas pautas em comum, como o anticomunismo. A presença desses grupos em diferentes lugares do aparelho estatal provocava a adoção de políticas contraditórias por parte do Estado. Dessa forma, não havia uma

23 O número de detenções envolvendo entorpecentes, divulgados pela imprensa, permite-nos vislumbrar parte do quadro repressivo: 630 presos em 1972; 370 em 1973; 250 em 1974; e 60 em 1975. Balanço completo do Festival de Inverno. Estado de Minas (Belo Horizonte), 27 jul. 1975, BU - UFMG, Belo Horizonte, Col. Esp., FI, cx. 1975/Recortes. 
unificação em termos de políticas culturais. Os setores conservadores promoviam uma pauta conservantista e moralizante, como no caso da censura, e os setores liberais, pautas modernizantes, como o incentivo ao desenvolvimento da indústria cultural e a reforma universitária (Motta, 2014). Muitas vezes, essas políticas culturais divergentes entravam em choque, como nos episódios de peças teatrais premiadas ou financiadas pelo SNT, que eram censuradas posteriormente (Garcia, 2013).

No caso do Festival de Inverno, sua continuidade estava relacionada à proeminência da reforma universitária promovida pela UFMG. A instituição abraçou o evento como exemplo de sucesso no campo do extensionismo, prática inabitual no âmbito universitário de então. Os artistas e professores promotores do Festival construíram um evento de grande prestígio no meio cultural e universitário, apoiado por interesses diversos, o que lhe garantia o financiamento. Mas também conseguiram criar um espaço de liberdade, permeado por práticas cotidianas de resistência. A reforma universitária, porém, estava inserida no processo de modernização conservadora autoritária (Motta, 2014). Em seu eixo modernizador, o Festival era inovador em termos de extensão universitária, de promoção cultural e de incentivo ao turismo. No eixo conservador autoritário, deveria se sujeitar às políticas censórias e repressivas do Estado. Desta forma, para dar continuidade ao Festival, seus organizadores procediam, muitas vezes, de forma ambígua e contraditória em relação à censura e a repressão.

No que se refere à repressão, por exemplo, foi construído um discurso de separação entre o festival em si, sério e respeitado, e o festival paralelo, o da "perdição" e dos "falsos turistas". ${ }^{24}$ Quando a repressão em Ouro Preto se tornava mais voraz, atrapalhando a tranquilidade do Festival e dos turistas, negociava-se com o governo uma flexibilização do aparelho repressivo (Aragão, 2009). Mas enviava, anualmente, ofício ao secretário de segurança, solicitando policiamento discreto, de preferência à

24 CARNEIRO, Plínio. Esclarecimento quanto ao sentido do Festival de Inverno e quanto às notícias policiais associadas ao referido Festival de Inverno, BU - UFMG, Belo Horizonte, Col. Esp., FI, cx. 1970/1, pasta 1.3. 
paisana, em todas as promoções culturais. ${ }^{25}$ Através dessas manobras, a universidade eximia-se da responsabilidade dos problemas que sucediam fora das atividades oficiais do evento. Contudo, a universidade ficava responsável pelo que acontecia no Festival em si. Cabia-lhe, assim, para manter as liberdades experimentadas e conquistadas, seguir as normas da censura e delinear os difíceis limiares da autocensura.

No final da década de 1960, junto ao fortalecimento das tendências autoritárias no governo federal, há um processo de politização da censura de diversões públicas, que incluía o teatro. Essa politização da censura teatral se dava pela proibição de peças que veiculavam temas políticos de esquerda ou críticos ao regime. Mas também por agregar sentido político a questões morais (Garcia, 2010). Setores conservadores acreditavam que o comunismo buscava expandir-se por meio da crítica aos costumes e valores morais da sociedade.

Em relação à censura, o papel dos organizadores do Festival seria o de acatar a decisão dos órgãos responsáveis. Verificar se as peças haviam sido liberadas ou não para apresentações. Se liberadas, subiam ao palco. Em caso de espetáculos programados que acabavam censurados, substituía-se a atividade. Foi o caso da peça As religiosas, de Eduardo Manet, pelo Teatro Macário, com direção de Celso Nunes, em 1973, substituído por um concerto de professores do evento. ${ }^{26} \mathrm{~A}$ organização do Festival não exercia um papel de censor, mas buscava acatar as decisões da censura. Mas o diálogo com a censura podia tornar-se mais complexo. Observe-se, por exemplo, a trajetória do Teatro Experimental.

O grupo surgiu no final da década de 1950, a partir de uma cisão no Teatro Universitário da UFMG (Dangelo, 2010). Em 1967, realizaram o espetáculo de abertura do Festival, com Escorial. No ano seguinte, apresentou seu maior sucesso, Oh! Oh! Oh! Minas Gerais, de Jonas Bloch

25 SC-169/69, BU - UFMG, Belo Horizonte, Col. Esp., FI, cx. 1969/1, pasta 1.7a. $N^{\circ} 244 / 70$, BU UFMG, Belo Horizonte, Col. Esp., FI, cx. 1970/2, pasta 2.1a. SC/n²96/71, BU - UFMG, Belo Horizonte, Col. Esp., FI, cx. 1971/2, pasta 2.1a. $S G / n^{\circ} 28 / 72$, BU - UFMG, Belo Horizonte, Col. Esp., FI, cx. 1972/4, pasta 4.1b.

26 Boletim: 7 Festival de Inverno, n. 35, 19 jul. 1973, BU - UFMG, Belo Horizonte, Col. Esp., FI, cx. 1973/1. 
e Jota Dangelo. O texto possuía referências relacionadas diretamente "ao momento social, político e econômico que o País em geral e Minas em particular" atravessavam (Bloch; Dângelo, 1968, p.5). Inspirado em Liberdade, liberdade, de Millôr Fernandes e Flávio Rangel, consistia numa colagem de textos literários e documentos históricos. Um meio de protesto e denúncia do regime arbitrário em que se vivia. A peça marcou uma rápida mudança de rumo estético do grupo, da vanguarda ao engajamento. Em dezembro de 1968, o espetáculo foi proibido em todo o território nacional (Dangelo, 2010).

Oh! Oh! Oh! Minas Gerais não teve problemas com a censura no Festival de Inverno, mas outra peça provocou grande indisposição com o público, com a imprensa e com a igreja. Em 1969, o Teatro Experimental apresentou Procura-se uma rosa, de Gláucio Gil. O texto do espetáculo possuía liberação da censura, porém sua única apresentação pelo grupo acabou ocorrendo em Ouro Preto. Segundo Jota Dangelo (2010, p.102), o texto não possuía maiores méritos, mas Carlos Alberto Ratton "transformou-o numa encenação alucinada e caótica, sob sua direção. A intenção velada do espetáculo era criticar o próprio Festival de Inverno, muito preocupado com uma imagem de respeitabilidade e seriedade que lhe servia de marca registrada. Derrubar este tabu, desmistificar esse pretenso intelectualismo".

Temos aqui, novamente, a questão da relação entre texto e cena no teatro experimental. A descrição realizada por Jota Dangelo permite uma aproximação da encenação de Ratton com a realizada por José Celso Martinez, um ano antes, para Roda viva. José Celso transformou o texto de Chico Buarque em espetáculo carnavalizante e paródico, que somava o "elemento da agressão, estética e comportamental, como procedimento básico da vanguarda”. A plateia como alvo de agressão, na busca de um choque de consciência, rumo a uma "crítica radical à sociedade e seus valores" (Napolitano, 2014, p.111-112). Aparentemente, Ratton adotou métodos semelhantes aos de José Celso e, igualmente, sofreu reações.

O público de Procura-se uma rosa sentiu-se agredido pela encenação e a trupe teve que sair escondida da cidade: "A população nos chamou 
de moleques, vândalos e outras coisas impublicáveis. Kombis percorreram a cidade, com equipamentos de som, exigindo até mesmo punição exemplar para 'o grupo que veio avacalhar o Festival de Inverno"' (Dangelo, 2010, p.102). A direção do Festival também não recebeu com agrado a apresentação e buscou reduzir os danos à imagem do evento. No dia seguinte ao espetáculo, além de emitir uma nota sobre o ocorrido, enviou carta ao diretor do Teatro Experimental, com cópias ao prefeito e ao clero. Dizia que o espetáculo não se ajustava à "dignidade e ao espírito do Festival de Inverno" e que professores, alunos, moradores e apoiadores haviam recebido o espetáculo como agressão e insulto. Um mês depois, o diretor do conselho de extensão enviava correspondência agradecendo a Sociedade Brasileira de Autores Teatrais, que proibira qualquer nova apresentação da peça pelo Teatro Experimental. ${ }^{27}$ Neste caso, o que podemos perceber é a soma de um mal-estar provocado pela encenação somado à necessidade de posicionamento do Festival e da universidade. Temos então o repúdio ao espetáculo e o pedido de desculpas à sociedade e às instituições apoiadoras.

A não participação do Living Theatre no Festival, em 1971, ressalta a ambiguidade dos produtores do evento em relação à censura. Não pela prisão em si, mas pela ausência do grupo na programação oficial. O Living, liderado por Judith Malina e Julian Beck, viera ao Brasil, em 1970, a convite de José Celso para um trabalho conjunto com o Teatro Oficina. Após rompimento com o grupo paulista, começaram a negociar com o produtor Júlio Varella a possibilidade de participarem do Festival de Inverno (Tytell, 1997). O projeto a ser apresentado em Ouro Preto era ambicioso e inovador. Consistia numa série de peças, em diferentes locais da cidade, ao longo de dez dias. Uma tentativa de romper com a arquitetura tradicional do teatro. ${ }^{28}$

27 Carta de Fábio do Nascimento Moura a Jota Dangelo, 24 jul. 1969. Carta de Rubens Romanelli a Grover Ferreira, diretor da SBAT, 25 ago. 1969. Carta de Grover Ferreira ao delegado regional do Departamento de Polícia Federal [com cópia para Gerson Boson, reitor da UFMG], 07 ago. 1969. BU - UFMG, Belo Horizonte, Col. Esp., FI, cx. 1969, pastas 1.7a/b.

28 Festival Ameaçado. Estado de Minas (Belo Horizonte), 1º cad., p.15, 18 maio 1980. 
O grupo mudou-se para Ouro Preto em fevereiro de 1971, mesmo sem receber uma confirmação da organização do evento. Desta forma, o Living Theatre transferiu-se para Ouro Preto sem garantia de contratação pelo Festival. Alugaram uma casa que foi organizada em forma de comunidade. Eram por volta de 20 pessoas morando juntas e dividindo todas as tarefas domésticas. Espaço onde se praticava o amor livre e fumava-se maconha, mas também onde realizavam ensaios, reuniões e recebiam jovens e artistas da cidade (Tytell, 1997). O grupo promovia oficinas com a comunidade ouro-pretana, entre outras atividades de pesquisa e ação. Uma série de oficinas foi realizada com o GETOP, onde eram trabalhadas e discutidas questões como a crítica ao espaço cênico tradicional, liberação corporal e desrepressão.

Paralelamente, ocorriam as negociações do Living Theatre com o Festival. Após meses de negociações, e mesmo com o grupo se oferecendo para apresentar gratuitamente após alegação de falta de verbas, sua participação foi recusada. Justificaram, posteriormente, não haver tempo de modificar a programação. ${ }^{29}$ Recentemente, a biografia de Júlio Varella revela outra explicação: "Apenas seis meses depois da instalação do grupo em Ouro Preto, a população da cidade, incluindo o clero, está escandalizada com o estilo de vida e o comportamento do grupo. A proposta, então, não é aceita pelo Festival” (Aragão, 2009, p.116). Desta forma, as informações sobre o estilo de vida libertário do grupo levou os organizadores a declinar. Era uma forma de proteger o evento, através de autocensura diante de possíveis escândalos e atritos com órgãos de censura e repressão.

Contraditoriamente, no mesmo ano, houve um episódio que contrariava a política de censura do governo. Os integrantes do GETOP incorporaram as reflexões e o aprendizado provenientes das oficinas realizadas com o Living. A peça Ômega, de criação coletiva, programada para a abertura do Festival, tecia crítica ao espaço cênico e à falta de liberdade.

29 Carta de Rubens Romanelli e Júlio Varella a Julian Beck, 29 mar. 1971, BU - UFMG, Belo Horizonte, Col. Esp., FI, cx. 1971/2, Pasta 2.1b. Festival Ameaçado. Estado de Minas (Belo Horizonte), $1^{\circ}$ cad., p.15, 18 maio 1980. 
Encenada no dia da prisão dos integrantes do Living, a apresentação foi realizada sob um clima tenso. Segundo entrevista realizada com os atores Victor Godoy e Quelé, havia também o problema de que a liberação por parte da censura ainda não havia sido expedida. Para driblar este fato, Sylvia Orthof, coordenadora do setor de teatro, comunicou ao público, antes do início da apresentação, de que não se tratava de um espetáculo, mas de um ensaio geral. ${ }^{30}$

Baseado nas obras de Sacher-Mashoc e Gilberto Freyre, O Legado de Caim tinha como tema a permanência das relações senhor/escravo na sociedade brasileira, responsáveis pela existência de um Estado autoritário (Tytell, 1997). Convictos no projeto e com meses de preparação, os membros do Living mantiveram os planos de apresentá-lo em Ouro Preto. Na rua, para onde haviam planejado. Contudo, o estilo de vida libertário e a interação com a comunidade chamou também a atenção dos órgãos de repressão. No primeiro dia de julho, a polícia invadiu a residência e prendeu, por posse de maconha, os membros do grupo, que foram levados para os cárceres do DOPS em Belo Horizonte. O Festival procurou desvincular-se o máximo possível do episódio, afirmando que os atores não estavam vinculados ao evento. Ao mesmo tempo, afirmavam o Living como um grupo importante e sério. ${ }^{31}$

A aproximação entre arte e vida, uma das bases do grupo, foi utilizada para transformar o próprio encarceramento em performance. Conforme Alessandra Vannucci (2015, p.204), foi "um processo teatral que não aconteceu como espetáculo, mas provocou uma espetacular auto exposição dos dispositivos de repressão do regime militar". O diário de Judith Malina (2008), publicado pelo Estado de Minas enquanto estava encarcerada, permite observar esses artifícios, tanto na forma dramatizada da escrita, a desconstruir a imagem negativa veiculada pela imprensa, quanto o aspecto subversivo do texto: "acatando

30 Entrevista com Victor Godoy e Osmar Alves de Oliveira Júnior (Quelé), em novembro de 2011, cedida a Leon Kaminski, Henrique Manoel Oliveira e equipe da TV UFOP.

31 Tóxicos no Festival de Ouro Preto: DOPS entra em ação. Gazeta Comercial (Juiz de Fora), 04 jul. 1971, BU - UFMG, Col. Esp., FI, cx. 1971/Recortes. 
preventivamente a censura imposta por estar presa, pode encenar a si mesma naquele cenário, driblando uma possível repressão. Nessa coincidência entre vida e arte, o diário é uma performance articulada como tática de resistência" (Vannucci, 2015, p.219-220). As primeiras seções do julgamento, no Fórum de Ouro Preto, aconteceram durante o Festival. Juntaram-se centenas de pessoas em protesto silencioso contra a prisão. No interior do Fórum, alguns dos atores também realizavam suas performances: um sentou-se na posição de meditação da ioga e rezava; outro abençoou o juiz; e um terceiro explicou que "a euforia de que falava na sua declaração não era causada por maconha, mas por suas experiências com macumba" (Malina, 2008, p.147).

A prisão dos integrantes do Living Theatre provocou repercussão internacional, que auxiliava na denúncia do arbítrio promovido pela ditadura. Protestos foram organizados em frente a órgãos diplomáticos brasileiros no exterior (Tytell, 1997; Green, 2009). No final de agosto, Médici decretava a expulsão dos atores estrangeiros: "a prisão determinou o surgimento de uma onda de protestos em várias partes do mundo, atribuindo ao Governo brasileiro conduta inamistosa para com a classe teatral, o que tem sido explorado pelos inimigos da nossa pátria, na campanha difamatória que empreendem contra o Brasil” (Malina, 2008, p.252).

Palco barroco, de luzes e sombras para a cena experimental brasileira, o Festival de Inverno conciliou e dialogou, não sem contradições, com diferentes políticas culturais de seu tempo. Foi, porém, lugar de encontro, zona de contato entre diversas disciplinas artísticas, espaço liberto, de criação. Mas a liberdade, como sempre, tem seus limites. Com a mudança da conjuntura econômica e política, o Festival deixaria de ser realizado em 1980, e trocava, no ano seguinte, Ouro Preto por Diamantina.

\section{Agradecimentos}

Agradeço à professora Miriam Hermeto pelo convite para participar do presente dossiê e ao professor Mateus Henrique Pereira pela orientação 
e por todo o apoio antes e depois da defesa da dissertação que deu origem a este artigo. Agradeço também aos avaliadores da revista pelos comentários e sugestões que contribuíram para o aprimoramento do texto e ao Adriano Menezes pela leitura e correções.

\section{REFERÊNCIAS BIBLIOGRÁFICAS}

APOCALYPSE, Álvaro. Álvaro Apocalypse: depoimento. Belo Horizonte: C/Arte, 2001.

AQUINO, Dulce. Anos 70, o Brasil e a dança. In: RISÉRIO, Antonio et al. Anos 70: trajetórias. São Paulo: Iluminuras/Itaú Cultural, 2005. p.99-194. ARAGÃO, José Carlos. Júlio Varella: 50 anos fazendo arte. Belo Horizonte: Comercial O Lutador, 2009.

BLOCH, Jonas; DÂNGELO, Jota. Oh! Oh! Oh! Minas Gerais. Belo Horizonte: Itatiaia, 1968.

BOGÉA, Inês. O Corpo, de lá para cá. In: BOGÉA, Inês (org.). Oito ou nove ensaios sobre o grupo corpo. São Paulo: Cosac Naifi, 2007. p.22-38. BRAGA, Humberto. Aspectos da história recente do teatro de animação no Brasil. Móin-móin, ano 3, n.4, p.343-373, 2007.

CAVALCANTI, Johana Albuquerque. Teatro experimental (1967-1978): pioneirismo e loucura à margem da agonia da esquerda. Tese (Doutorado em Artes Cênicas) - Universidade de São Paulo. São Paulo, 2012.

DANGELO, Jota. Os anos heroicos do teatro em Minas. São Paulo: Atheneu, 2010.

GARCIA, Miliandre. "Ou vocês mudam ou acabam": aspectos políticos da censura teatral (1964-1985). Topoi, vol. 11, n. 21, p.235-259, 2010.

GARCIA, Miliandre. Políticas culturais na ditadura militar: a gestão de Orlando Miranda no SNT e os paradoxos da "hegemônia cultural de esquerda” (1974-1979). In: NAPOLITANO, Marcos; CZAJKA, Rodrigo; MOTTA, Rodrigo Patto Sá (orgs.). Comunistas brasileiros. Belo Horizonte: Ed. Ufmg, 2013. p.131-150.

GREEN, James. Apesar de vocês: oposição à ditadura brasileira nos Estados Unidos, 1964-1985. São Paulo: Companhia das Letras, 2009. 
HERMETO, Miriam. O engajamento, entre a intenção e o gesto: o campo teatral brasileiro durante a ditadura militar. In: REIS, Daniel Aarão; RIDENTI, Marcelo; MOTTA, Rodrigo Patto Sá (orgs.). A ditadura que mudou o Brasil: 50 anos do golpe de 1964. Rio de Janeiro: Zahar, 2014. p.203-215.

HERRERA, Rufo. Prefácio. In: MEDEIROS, Ione de. Grupo Oficcina Multimédia: 30 anos de integração das artes no teatro. Belo Horizonte: I. T. Medeiros, 2007. p.9-11.

LEÃO, Raimundo. Transas da cena em transe: teatro e contracultura na Bahia. Salvador: Edufba, 2009.

LOVAGLIO, Vânia Carvalho. Música contemporânea em Minas Gerais: os Encontros de Compositores Latino-americanos de Belo Horizonte (1986-2002). Tese (Doutorado em História) - Universidade Federal de Uberlândia. Uberlândia, 2010.

MACIEL, Luiz Carlos. Teatro anos 70. In: RISÉRIO, Antonio et al. Anos 70: trajetórias. São Paulo: Iluminuras/Itaú Cultural, 2005. p.105-109.

MALAFAIA, Marcos. Giramundo: memórias de um teatro de bonecos. Móin-móin, ano 2, n. 2, p.180-200, 2006.

MALINA, Judith. Diário de Judith Malina: o Living Theatre em Minas Gerais. Belo Horizonte: Arquivo Público Mineiro, 2008.

MEDEIROS, Ione de. Grupo Oficcina Multimédia: 30 anos de integração das artes no teatro. Belo Horizonte: I. T. Medeiros, 2007.

MICHALSKI, Yan. O teatro sob pressão. Rio de Janeiro: Zahar, 1985.

MOTTA, Rodrigo Patto Sá. As universidades e o regime militar: cultura política e modernização autoritária. Rio de Janeiro: Zahar, 2014.

NAPOLITANO, Marcos. 1964: história do regime militar brasileiro. São Paulo: Contexto, 2014.

PAOLIELLO, Guilherme. A circulação da linguagem musical: o caso da Fundação de Educação Artística. Tese (Doutorado em Educação) - Universidade Federal de Minas Gerais. Belo Horizonte, 2007.

PAVIS, Patrice. Dicionário de Teatro. São Paulo: Perspectiva, 2008. PEDROSO, Lucio Fernandes. Transgressão do Bom Fim. Dissertação (Mestrado em História) - Universidade Federal do Rio Grande do Sul. Porto Alegre, 2009. 
PIMENTA, Aloísio. Universidade: a destruição de uma experiência democrática. Petrópolis: Vozes, 1984.

PINTA, Maria Fernanda. Teatro expandido en el Di Tella: la escena experimental argentina em los años 60. Buenos Aires: Biblos, 2013.

REIS, Daniel Aarão. Ditadura e democracia no Brasil. Rio de Janeiro: Zahar, 2014.

REIS, Sérgio. Rodrigo Pederneiras e o Grupo Corpo. São Paulo: Imprensa Oficial do Estado de São Paulo, 2008.

RIBEIRO, Marília Andrés. Neovanguardas: Belo Horizonte - anos 60. Belo Horizonte: C/Arte, 1997.

ROLLEMBERG, Denise; QUADRAT, Samantha Viz (orgs.). A construção social dos regimes autoritários, vol. 2: Brasil e América Latina. Rio de Janeiro: Civilização Brasileira, 2011.

TYTELL, John. The Living Theatre: art, exile and outrage. Londres: Methuen Drama, 1997.

VANNUCCI, Alessandra. Legado de Caim: a jornada brasileira do Living Theatre (1970-71). Sala Preta, vol. 15, n.1, p.203-224, 2015.

VIEIRA, Beatriz de Moraes. A palavra perplexa: experiência histórica e poesia no Brasil nos anos 1970. Tese (Doutorado em História) - Universidade Federal Fluminense. Niterói, 2007. 